\title{
Mechanical and thermal properties of tungsten carbide - graphite nanoparticles nanocomposites
}

\author{
Kamil Kornaus", Agnieszka Gubernat, Dariusz Zientara, Paweł Rutkowski, Ludosław Stobierski \\ AGH University of Science and Technology, Faculty of Materials Science and Ceramics, Department of Ceramics and \\ Refractories, al. Mickiewicza 30, 30-059 Krakow, Poland \\ "Corresponding author: e-mail: kornaus@agh.edu.pl
}

\begin{abstract}
Previous studies concerning pure tungsten carbide polycrystalline materials revealed that nanolayers of graphite located between WC grains improve its thermal properties. What is more, pressure-induced orientation of graphene nano platelets (GNP) in hot pressed silicon nitride-graphene composites results in anisotropy of thermal conductivity. Aim of this study was to investigate if addition of GNP to WC will improve its thermal properties. For this purpose, tungsten carbide with $0.5-6 \mathrm{wt} . \%$ of GNP(12)-additive underwent hot pressing. The microstructure observations performed by SEM microscopy. The anisotropy was determined via ultrasonic measurements. The following mechanical properties were evaluated: Vickers hardness, bending strength, fracture toughness KIc. The influence of GNP(12) addition on oxidation resistance and thermal conductivity was examined. It was possible to manufacture hot-pressed WC-graphene composites with oriented GNP(12) particles, however, the addition of graphene decreased both thermal and mechanical properties of the material.
\end{abstract}

Keywords: graphene, composites, thermal and mechanical properties, tungsten carbide, hot pressing.

\section{INTRODUCTION}

Materials composed of various forms of carbon are being continuously investigated by material scientist in order to improve their applications in several fields of technique and industry. Tungsten carbide (WC) is very desirable material due to its attractive mechanical, physical and chemical properties such as high hardness, high melting point, good electrical and thermal conductivity, and high corrosion resistance ${ }^{1}$. WC is usually sintered with the addition of a metal such as cobalt or nickel. This method allows obtaining dense polycrystals at low temperature $\left(1500-1600^{\circ} \mathrm{C}\right)$. This materials called cemented carbides. However, the presence of the metallic binding phase, reduces its hardness, chemical resistance, or maximum operating temperature. It is also possible to obtain a dense polycrystalline sintered carbides with minor content of a precursor of amorphous form of the active carbon ${ }^{2-4}$.

Another noteworthy material is graphene and graphenlike materials such graphene nano platelets (GNP) addition of which in the most cases improves the thermal or electrical conductivity of a material when combined with advanced ceramics, as were presented in numerous studies $^{6-9}$. Anisotropy of properties usually occurs in hot-pressed materials when specific, directional orientation of graphene layers in composite microstructure is observed. Another effect in graphene composites is the improvement of the mechanical properties by bridging cracks through the layers of graphene by mechanism analogous to that in fibrous composites ${ }^{10-19}$. What is more, improvement of the tribological properties in composites containing platelet graphene is observed ${ }^{19,20}$.

To our knowledge, there is no literature which describes the combination of neither WC/graphene nor WC/GNP.

\section{EXPERIMENTAL MATERIAL AND METHODS}

WC - GNP(12) composites were prepared using commercial powders of submicron tungsten carbide (ABCR GmbH\&CoKG no. AB173079) and nanometric graphene flakes (average flakes thickness $12 \mathrm{~nm}, 30-50$ monolayers with average particle (lateral) size: $4.5 \mu \mathrm{m}(1.5-10)$, Grade AO-2 of Graphene Laboratories) as a substrates. GNP(12) additive was $0.5,2.0,4.0$ and $6.0 \mathrm{wt} \%$., respectively. The powders mixtures were homogenized in dry isopropanol media for 5 hours using rotary-vibratory mill. Cemented tungsten carbide WC-Co grinding media was used. Alcohol was removed using an IR irradiator, then granulated powders were sintered by hot-pressing technique (Thermal Technology LLC) at $1850^{\circ} \mathrm{C}$ for $1 \mathrm{~h}$ under $25 \mathrm{MPa}$ in argon flow. Density of obtained materials was measured by Archimedes method in water. Phase composition and graphene phase identification has been determined by XRD (PANalytical Empyrean) and diffraction Raman spectroscopy (Horriba Yvon Jobin LabRAM HR) methods. Microstructure of the samples was observed by SEM microscope (Nona Nano SEM 200, FEI Company).

The measurements of Vickers's hardness (Future - Tech Corp FV-700 apparatus) were taken on metallographic sections of composites. The samples were polished (Struers Rotopol 25) and chemically etched in molten alkali salts $\left(25 \% \mathrm{KNO}_{3}+75 \% \mathrm{KOH} ; 480^{\circ} \mathrm{C}\right)$ in order to allow microstructure observation of the material. The measurements of bending strength were performed using three point test (Zwick-Roell Z020). The fracture toughness was tested by single-edge notched beam method (SENB). The critical stress intensity factor was calculated based on Evans formula. The anisotropy of elastic wave velocity was measured by ultrasonic method using UZP-1 (INCO-VERITAS) apparatus. Measurements of thermal stability were performed in air flow up to $1000^{\circ} \mathrm{C}$ by means of differential scanning calorimetry (DSC) with thermogravimetric (TG) mode measurements by Netzsch 449 F3 Jupiter. Laser flash analysis (Netzsch LFA 427) method was used to determine thermal diffusivity. The measurement of sintered bodies was in parallel direction to the applied pressure using "Radiation + pulse correction" model. Then, on the basis of the equation 
(1) and the available data, the coefficient of thermal conductivity was calculated.

$$
\lambda=\alpha \cdot C_{p} \cdot \rho\left[\frac{W}{m \cdot d e g}\right]
$$

where:

$\alpha$ - thermal diffusivity,

$\mathrm{C}_{\mathrm{p}}$ - specific heat,

Q - apparent density.

\section{RESULTS AND DISCUSSION}

Density of the samples was measured by the Archimedes method and their theoretical density was calculated by the rule of mixtures assuming densities of $15.6 \mathrm{~g} / \mathrm{cm}^{3}$ for WC and $2.07 \mathrm{~g} / \mathrm{cm}^{3}$ for GNPs. Relative density of the composites is in the range from 94 to $98 \%$ (Table 1)

Table 1. Densities of obtained materials

\begin{tabular}{|l|c|c|}
\hline Amount of graphene [\%] & $\begin{array}{c}\text { Density } \\
{\left[\mathrm{g} / \mathrm{cm}^{3}\right]}\end{array}$ & Relative density [\%] \\
\hline 0.50 & 14.89 & 97.31 \\
\hline 2.00 & 13.70 & 98.07 \\
\hline 4.00 & 11.82 & 94.46 \\
\hline 6.00 & 11.08 & 97.70 \\
\hline
\end{tabular}

The morphology of the GNP(12) is presented in the pictures obtained by AFM and SEM - Figures 1 and

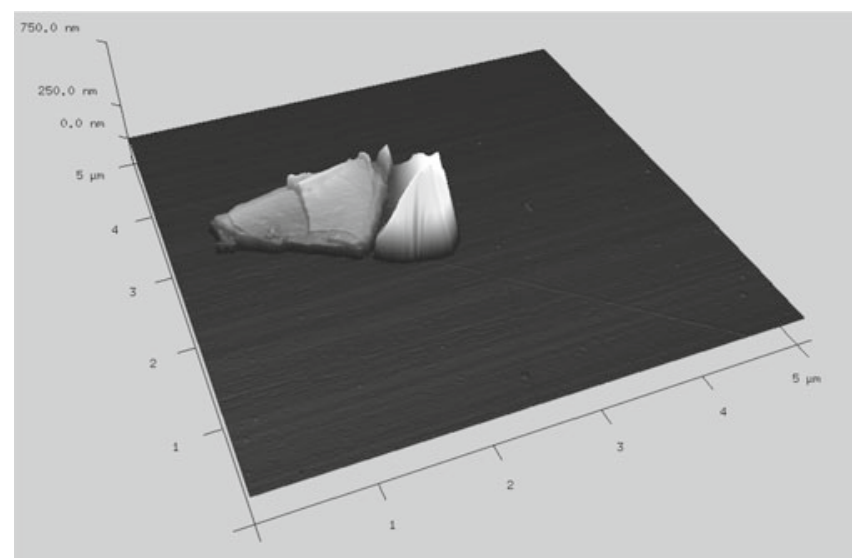

Figure 1. The morphology of the GNP(12) obtained by AFM method

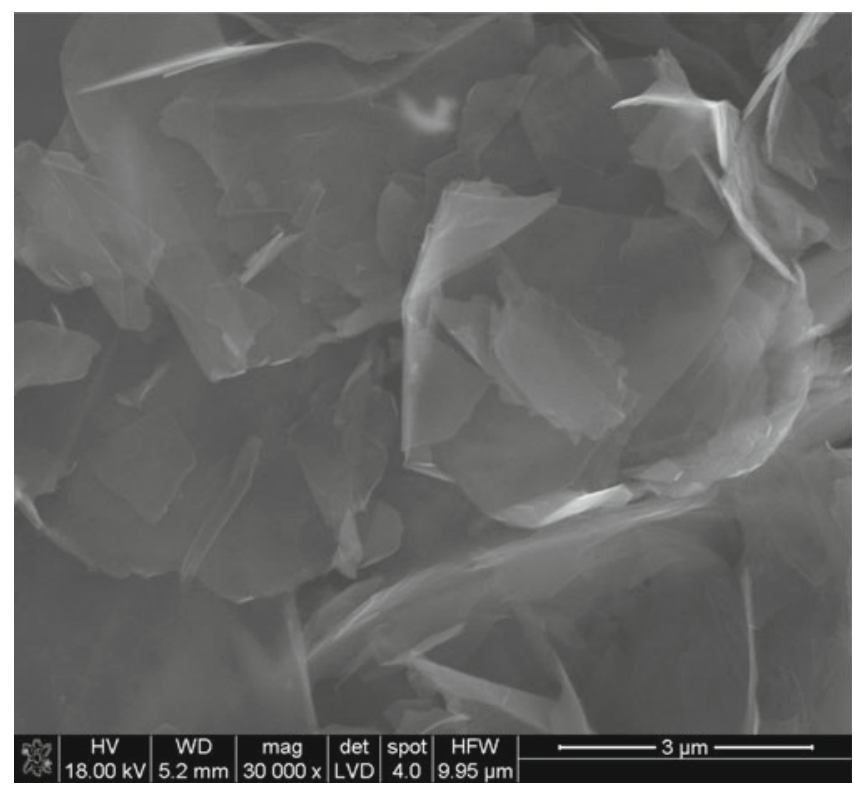

Figure 2. SEM image of the pristine GNP(12) powder
2. The strong tendency to agglomerate in packages with a thickness up to $150 \mathrm{~nm}$ can be observed. Therefore, GNP(12) additive should be concerned as nanographite.

Figures 3 and 4 show the Raman spectra of composites in the perpendicular $(\mathrm{P})$ and parallel $(\mathrm{R})$ directions to the axis of hot-pressing. Raman spectra of graphene and graphite have three characteristic active modes: first one approximately $1350 \mathrm{~cm}^{-1}$ called D band, G band about $1575 \mathrm{~cm}^{-1}$ and 2D band approximately $2700 \mathrm{~cm}^{-1}$. Last one is related with layered structure of graphite or graphene. 2D band peak for pure monolayer graphene is much more intense and sharper as compared to the 2D band in multi-layer graphene GNP(12 $)^{21-23}$. Low intensity and high width of $2 \mathrm{D}$ brand peak of pure GNP(12) powder confirm conclusion drawn from AFM and SEM observations, which is that GNP(12) should be regarded as nanographite. Moreover, peaks registered in the direction parallel to the axis of compression are more intense comparing to perpendicular direction, which confirms space orientation of nanographite platelets. The widening and decrease in 2D band peak intensity with increasing amount of GNP(12) addition (parallel direction) indicate strong agglomeration or even graphitization progression of additive GNP(12). Similar information is provided by XRD analysis (Fig. 5), which identifies WC and graphite phases in composite. Presumably, these results testify to the fact, that during homogenization process nanographite (GNP 12) is strongly agglomerated,

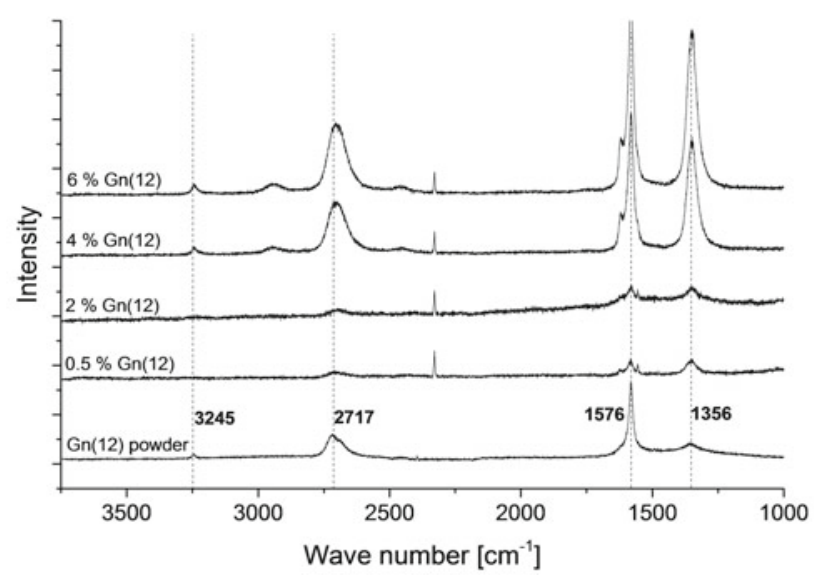

Figure 3. Results of the Raman spectroscopy of the tungsten carbide-nanographite composites in perpendicular direction

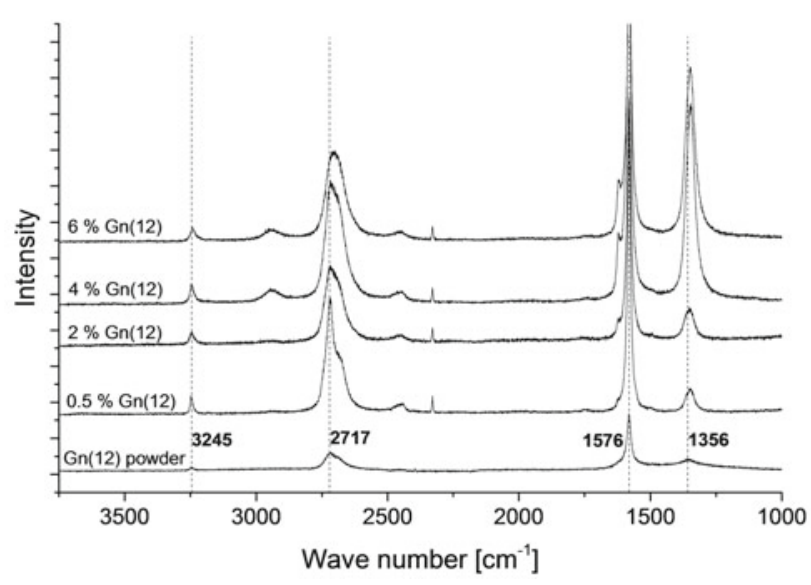

Figure 4. Results of the Raman spectroscopy of the tungsten carbide-nanographite composites in parallel direction 


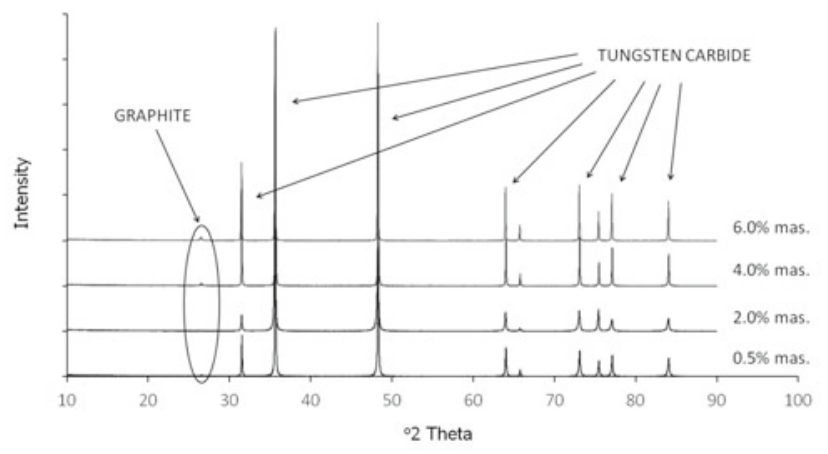

Figure 5. XRD analysis of WC-nanographite composites

as well as hot-pressing leads to further graphitization. The orientation of nanographite platelets is visible in all samples, but mostly in the case of composites with the highest content of GNP(12) (Figs. 6 and 7). Nanographite plateletes are arranged in a direction perpendicular to the load applied during HP process. This fact has been confirmed by ultrasonic measurements.

The results presented in Figure 8 indicate a significant anisotropy of ultrasonic wave transition velocity in direction perpendicular to the pressing direction. The anisotropy increases with the amount of nanographite in the material from the $\sim 10 \%$ for $0.5 \%$ addition of GNP(12) to $\sim 53-55 \%$ for the $4 \%$ and $6 \%$ GNP(12) content. Similar anisotropy was observed in previous studies of Rutkowski et al., 7 .

Oxidation resistance of sintered composites was tested in air flow. As results has shown (Figs. 9-11), composites with $0.5 / 2.0 \mathrm{wt} . \%$ of nanographite additive have the same oxidation resistance as single-phase WC (up to $700^{\circ} \mathrm{C}$ ). Increasing amount of nanographite additive causes a decrease in the oxidation resistance of composites, which is caused by a lower resistance to oxidation of the carbon additive in comparison to the WC matrix. The measurement taken by the laser flash analysis (LFA) method allowed determination of the thermal conductivity of tested materials (Fig. 12). Addition of small amount (0.5 $\mathrm{wt} \%$ ) of nanographite leads to improvement of composite's thermal conductivity coefficient when compared to single phase WC polycrystal. Lower thermal conductivity coefficient of composites with a higher content of the

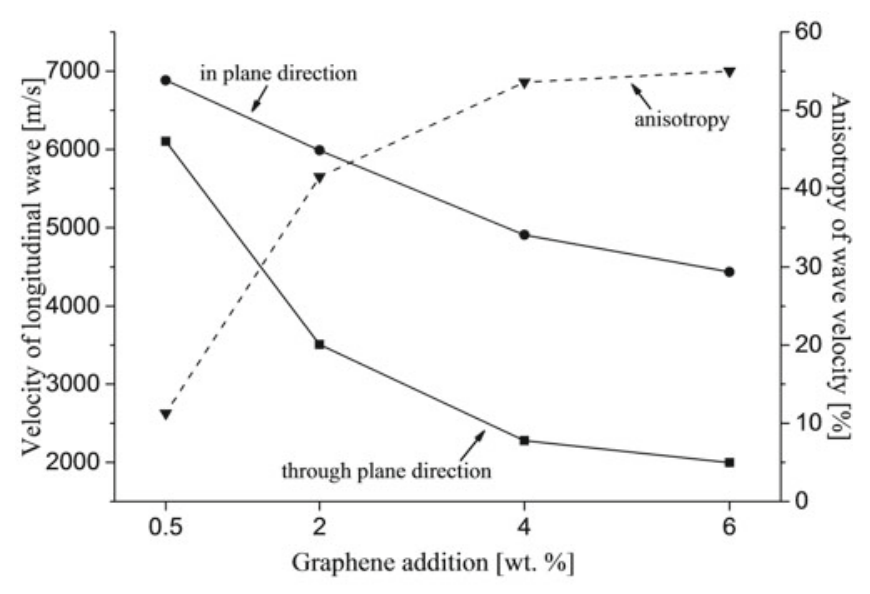

Figure 7. Comparison of anisotropy of ultrasonic wave velocity in the investigated materials

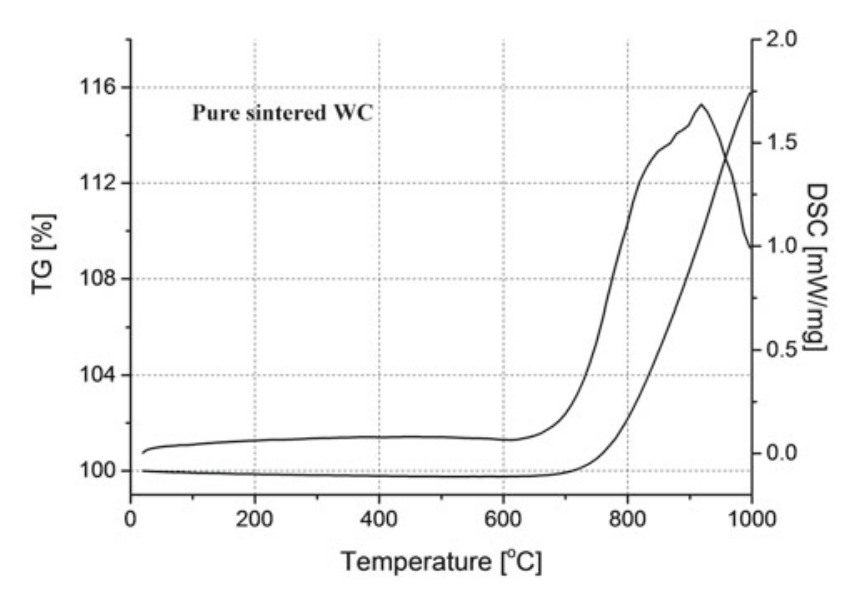

Figure 8. Results of DSC and TG measurements of pure sintered tungsten carbide

GNP(12) most likely results of nanographite agglomeration and graphitization. It is supposed that the value of thermal diffusivity will be higher in the direction perpendicular to pressing axis, which means graphene flake direction. Such measurement will be performed in the further studies.

The measurements of mechanical properties i.e. bending strength and Vickers hardness were performed in both perpendicular $(\mathrm{P})$ and parallel $(\mathrm{R})$ directions to the axis of compression. Based on the results (Figs. 13 and

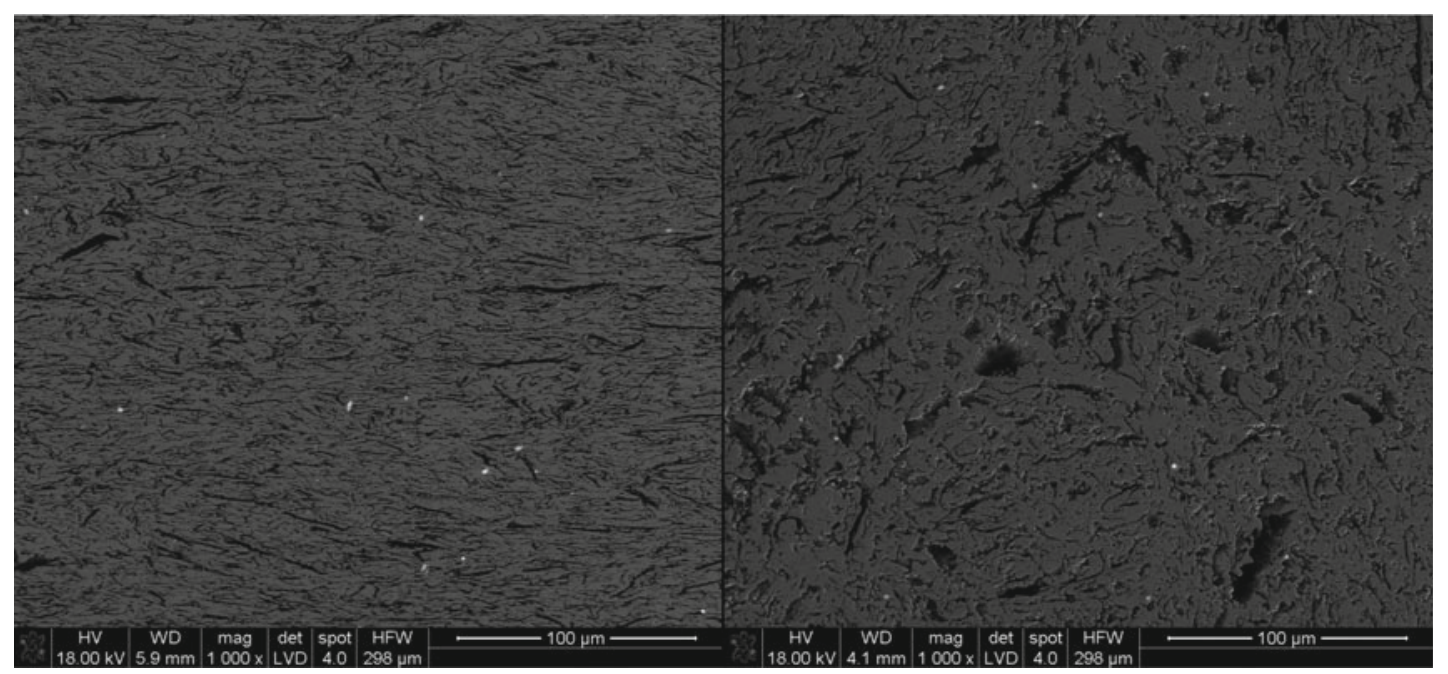

Figure 6. The sectional view of WC-nanographite composite in a direction parallel (left side) and perpendicular (right side) to the orientation of nanographite 


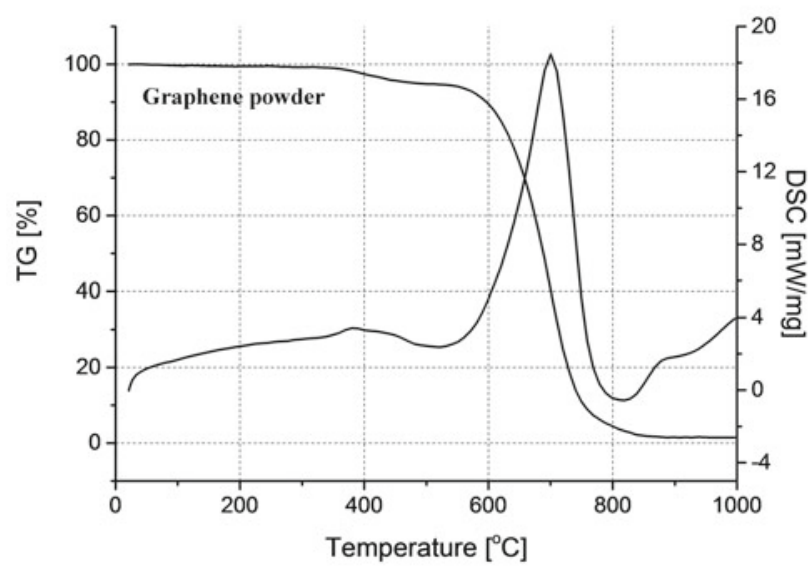

Figure 9. Results of DSC and TG measurements of pure GNP(12) powder

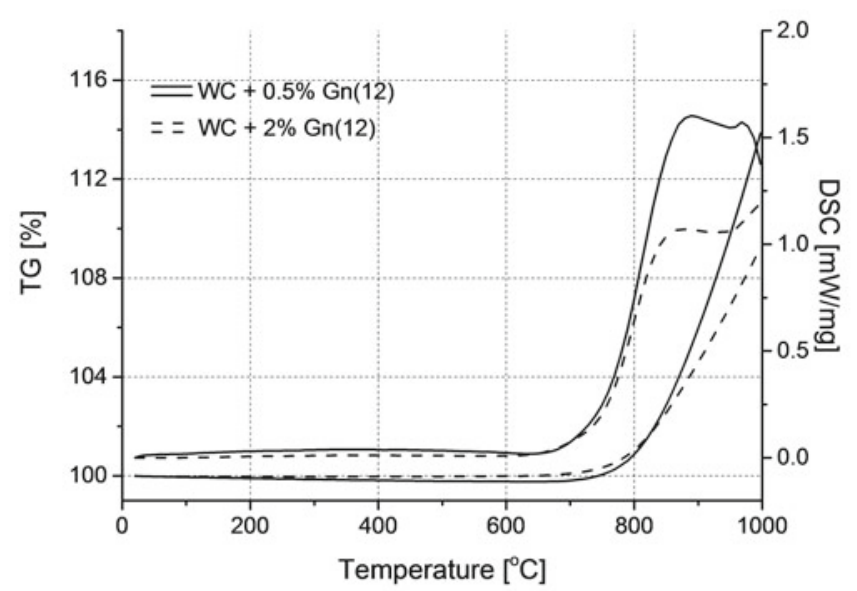

Figure 10. Results of DSC and TG measurements of WC-GNP(12) composites

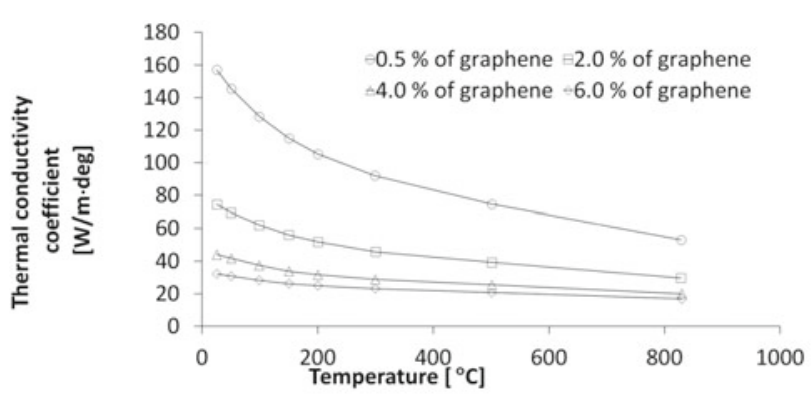

Figure 11. Thermal conductivity versus temperature of hot-pressed Tungsten carbide-GNP(12) composites registered in pressing direction

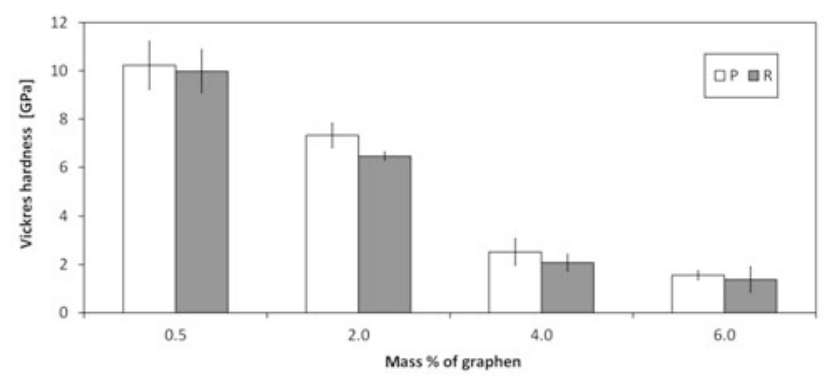

Figure 12. Comparison of hardness WC-nanographite composites in both parallel and perpendicular directions to the axis of pressing
14), it is evident that, these values of bending strength and Vickers hardness are similar to each other within the same content of GNP(12). Increasing addition of nanographite led to a rapid decline of properties mentioned above. The composite containing the lowest addition had nearly five times higher hardness and approximately three times higher bending strength than the material with the highest amount of nanographite. The tendency was similar regarding the fracture toughness (Fig. 15). Material with lowest addition had the highest $\mathrm{K}_{\mathrm{Ic}}$ coefficient $\left(\sim 6.3 \mathrm{MPa} \cdot \mathrm{m}^{0.5}\right)$. All tested mechanical properties of nanocomposites were reduced comparing to those typical for single-phase tungsten carbide ${ }^{24}$.
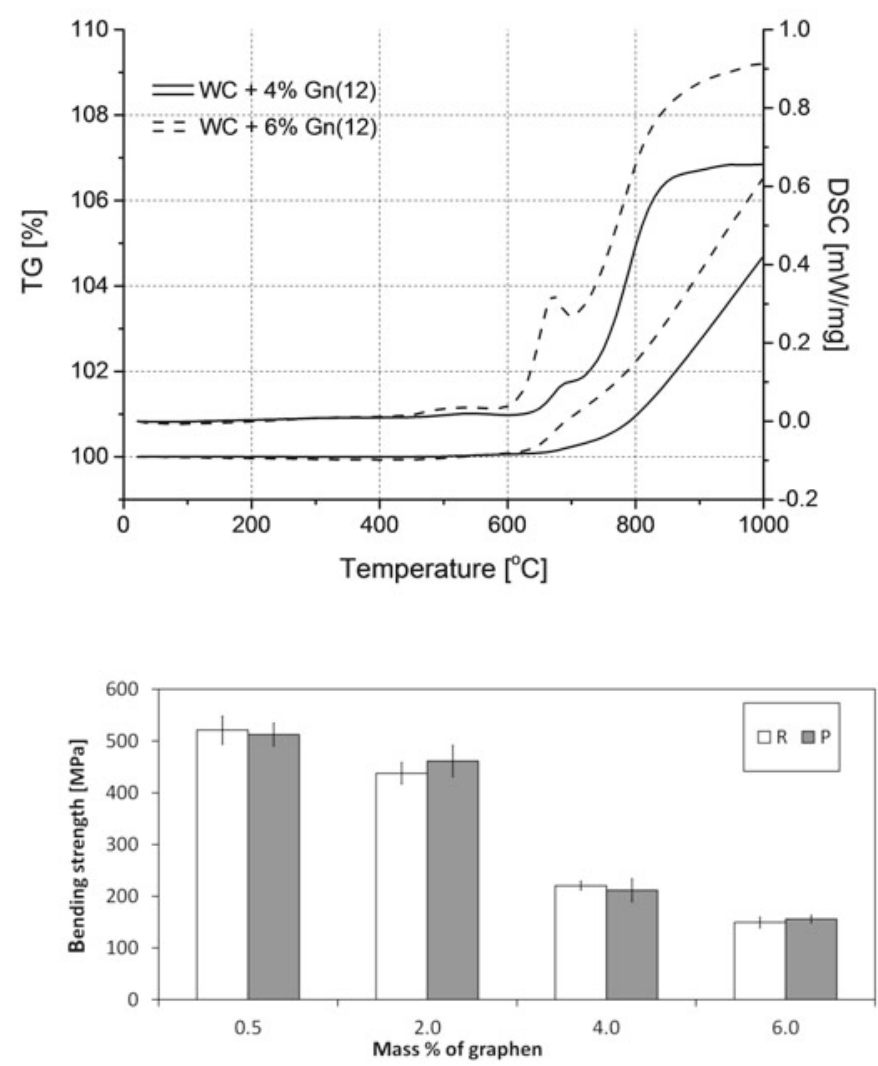

Figure 13. Comparison of bending strength WC-nanographite composites in both parallel and perpendicular directions to the axis of pressing

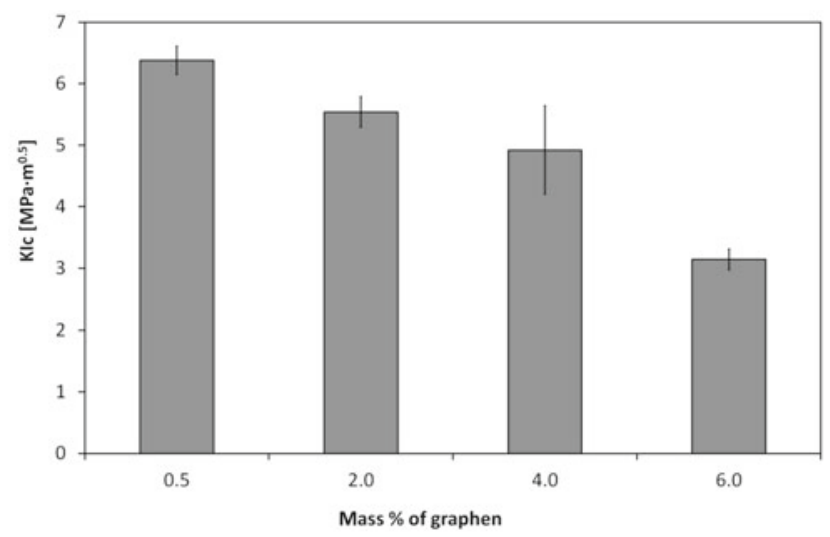

Figure 14. Results of fracture toughness measurements in WC-GNP(12) composites 


\section{CONCLUSIONS}

- It was possible to manufacture the dense WC-GNP(12) composites with oriented nanographite particles by hot-pressing method.

- The XRD analysis and Raman spectroscopy confirmed existence of WC and nanographite phases in composites.

- The high level of agglomeration of GNP(12) additive is likely to be the reason for substantial deterioration of its mechanical and thermal properties in comparison with single-phase tungsten carbide polycrystal.

- Studies indicate the necessity of application a different method of homogenization of both powders, which will exclude the strong agglomeration of nanographite.

\section{ACKNOWLEDGEMENTS}

The study constitutes a part of the project no. GRAF-TECH/ NCBR/03/05/2012 "Ceramic - graphene composites for cutting tools and devices parts with unique properties".

\section{LITERUTRE CITED}

1. Toth, LE. Transition metal carbides and nitrides. New York: Academic Press; 1971.

2. Gubernat, A. \& Stobierski, L. (2009). Wegliki metalopodobne Cz. I. Badania nad spiekaniem. Cer. Mat. 61(2), 113-118 from PTCer database on the World Wide Web: http://ptcer. $\mathrm{pl} / \mathrm{mccm} / \mathrm{pl} / \mathrm{szczegoly-artykulu} / 61 / 2 / 139$

3. Cha, S.I. \& Hong, S.H. (2003). Microstructures of binderless tungsten carbides sintered by spark plasma sintering process. Mater. Sci. Eng. A 356(1), 381-389. DOI: 10.1016/ S0921-5093(03)00151-5.

4. Zhao, J., Holland, T., Unuvar, C. \& Munir, Z.A. (2009). Sparking plasma sintering of nanometric tungsten carbide. Int. J. Refract. Met. Hard Mater. 27(1), 130-139. DOI: 10.1016/j.ijrmhm.2008.06.004.

5. Zhu, Y., Murali, S., Cai, W., Li, X., Suk, J.W., Potts, J.R. \& Ruoff, R.S. (2010). Graphene and graphene oxide: synthesis, properties, and applications. Adv. Mater. 22(35), 3906-3924. DOI: 10.3144/expresspolymlett.2011.79.

6. Ramirez, C., Figueiredo, F.M., Miranzo, P., Poza, P. \& Osendi, M.I. (2012). Graphene nanoplatelet/silicon nitride composites with high electrical conductivity. Carbon 50(10), 36073615. DOI:10.1016/j.carbon.2012.03.031.

7. Rutkowski, P., Klimczyk, P., Jaworska, L., Stobierski, L. \& Dubiel, A. (2015) Thermal properties of pressure sintered alumina-graphene composites. J. Therm. Anal. Calorim. 1-10 DOI: 10.1007/s10973-015-4694-x.

8. Rutkowski, P., Stobierski, L. \& Górny, G. (2014). Thermal stability and conductivity of hot-pressed $\mathrm{Si}_{3} \mathrm{~N}_{4}$-graphene composites. J. Therm. Anal. Calorim. 116(1), 321-328. DOI: 10.1007/s10973-013-3565-6.

9. Ramírez, C., Vega-Diaz, S.M., Morelos-Gomez, A., Figueiredo, F.M., Terrones, M., Osendi, M.I. \& Miranzo, P. (2013). Synthesis of conducting graphene $/ \mathrm{Si}_{3} \mathrm{~N}_{4}$ composites by spark plasma sintering. Carbon 57, 425-432. DOI: $10.1016 / \mathrm{j}$. carbon.2013.02.015.

10. Fan, Y., Estili, M., Igarashi, G., Jiang, W. \& Kawasaki, A. (2014). The effect of homogeneously dispersed few-layer graphene on microstructure and mechanical properties of $\mathrm{Al}_{2} \mathrm{O}_{3}$ nanocomposites. J. Eur. Soc. Ceram. 34(2), 443-451. DOI: 10.1016/j.jeurceramsoc.2013.08.035.

11. Liu, J., Yan, H., Reece, M.J. \& Jiang, K. (2012). Toughening of zirconia/alumina composites by the addition of graphene platelets. J. Eur. Soc. Ceram. 32(16), 4185-4193. DOI: 10.1016/j. jeurceramsoc.2012.07.007.
12. Kvetková, L., Duszová, A., Kašiarová, M., Dorčáková, F., Dusza, J. \& Balázsi, C. (2013). Influence of processing on fracture toughness of $\mathrm{Si}_{3} \mathrm{~N}_{4}+$ graphene platelet composites. J. Eur. Soc. Ceram. 33(12), 2299-2304. DOI: 10.1016/j.jeurceramsoc.2013.01.025.

13. Dusza, J., Morgiel, J., Duszová, A., Kvetková, L., Nosko, M., Kun, P. \& Balázsi, C. (2012). Microstructure and fracture toughness of $\mathrm{Si}_{3} \mathrm{~N}_{4}+$ graphene platelet composites. J. Eur. Soc. Ceram. 32(12), 3389-3397. DOI: 10.1016/j.jeurceramsoc.2012.04.022.

14. Kvetková, L., Duszová, A., Hvizdoš, P., Dusza, J., Kun, P. \& Balázsi, C. (2012). Fracture toughness and toughening mechanisms in graphene platelet reinforced Si $3 \mathrm{~N} 4$ composites. Scr. Mat. 66(10), 793-796. DOI: 10.1016/j.scriptamat.2012.02.009. 15. Yazdani, B., Xia, Y., Ahmad, I. \& Zhu, Y. (2015). Graphene and carbon nanotube (GNT)-reinforced alumina nanocomposites. J. Eur. Soc. Ceram. 35(1), 179-186. DOI: 10.1016/j. jeurceramsoc.2014.08.043.

16. Ramirez, C., Miranzo, P., Belmonte, M., Osendi, M.I., Poza, P., Vega-Diaz, S.M. \& Terrones, M. (2014). Extraordinary toughening enhancement and flexural strength in $\mathrm{Si}_{3} \mathrm{~N}_{4}$ composites using graphene sheets. J. Eur. Soc. Ceram. 34(2), 161-169. DOI: 10.1016/j.jeurceramsoc.2013.08.039.

17. Ramirez, C. \& Osendi, M.I. (2014). Toughening in ceramics containing graphene fillers. Cer. Int. 40(7), 11187-11192. DOI: 10.1016/j.ceramint.2014.03.150.

18. Nieto, A. Lahiri, D. \& Agarwal, A. (2013). Graphene NanoPlatelets reinforced tantalum carbide consolidated by spark plasma sintering. Mater. Sci. Eng. A, 582, 338-346. DOI: 10.1016/j.msea.2013.06.006.

19. Rutkowski, P., Stobierski, L., Zientara, D., Jaworska, L., Klimczyk, P. \& Urbanik, M. (2015). The influence of the graphene additive on mechanical properties and wear of hotpressed $\mathrm{Si}_{3} \mathrm{~N}_{4}$ matrix composites. J. Eur. Soc. Ceram. 35(1), 87-94. DOI: 10.1016/j.jeurceramsoc.2014.08.004.

20. Hvizdoš, P., Dusza, J. \& Balázsi, C. (2013). Tribological properties of $\mathrm{Si}_{3} \mathrm{~N}_{4}$-graphene nanocomposites. J. Eur. Soc. Ceram. 33(12), 2359-2364. DOI: 10.1016/j.jeurceramsoc.2013.03.035.

21. Tuinstra, F. \& Koenig, J.L. (1970). Raman spectrum of graphite. J. Chem. Phys. 53,1126-1130. DOI: 10.1063/1.1674108. 22. Ramirez, C., \& Osendi, M.I. (2013). Characterization of graphene nanoplatelets-Si $3 \mathrm{~N} 4$ composites by Raman spectroscopy. J. Eur. Soc. Ceram. 33(3), 471-477. DOI: 10.1016/j. jeurceramsoc.2012.09.014.

23. Zheng, Yan \& Andrew, R. Barron, Characterization of Graphene by Raman Spectroscopy, retrived 17 September, 2015. from: http://cnx.org/contents/f06226c5-c2a4-4798-9c75-b016acea73cd@2/Characterization-of-Graphene-b

24. Gubernat, A., Rutkowski, P., Grabowski, G. \& Zientara, D. (2014). Hot pressing of tungsten carbide with and without sintering additives. Int. J. Refract. Met. Hard Mater. 43, 193-199. DOI: 10.1016/j.ijrmhm.2013.12.002. 